\title{
2019 Lathisms: Latinxs and Hispanics in the Mathematical Sciences
}

\section{Pamela E. Harris, Alicia Prieto Langarica, and Luis Sordo Vieira}

Lathisms (Latinxs and Hispanics in Mathematical Sciences, www. 1athisms.org) provides an accessible platform that features outstanding research, teaching, mentoring, and service contributions of Latinxs and Hispanics to the mathematical sciences. Since 2016, Lathisms has featured 91 mathematicians, who are highlighted one per day during US Hispanic Heritage Month, which runs from September 15 to October 15 . This year, we are highlighting the work of Latinx and Hispanic mathematics educators.

The Lathisms honorees demonstrate a strong commitment to the advancement of Latinxs and Hispanics in the mathematical sciences, and we are excited to highlight their outstanding contributions. The 2019 Lathisms calendar continues this tradition and features mathematics educators, some of whom will be interviewed by Evelyn Lamb as part of our Lathisms podcast, made possible by the continued support of the Mathematical Association of America via a Tensor-SUMMA grant. New to the website this year are individual posters of each honoree, which will be freely available for download.

We present here the profiles of four of the 2019 Lathisms honorees. These honorees were selected to illus-

Pamela E. Harris is an assistant professor at Williams College. Her email address is pame1a.e.harris@wi11iams. edu.

Alicia Prieto-Langarica is an associate professor at Youngstown State University. Her email address is aprietolangarica@ysu.edu.

Luis Sordo Vieira is a postdoctoral associate at The Jackson Laboratory for Genomic Medicine. His email address is 1uis.sordovieira@jax.org.

Communicated by Notices associate editor Stephan Ramon Garcia.

For permission to reprint this article, please contact: reprint-permission aams.org.

DOI: https://dx.doi.org/10.1090/noti1935 trate the diversity within the Lathisms community in terms of research area and career stage.

\section{Hortensia Soto}

Hispanic Heritage Month means someone recognizes that we contribute to this country. It means that the sacrifice that my parents made for us was not in vain. It means that the work that my elementary teachers did for me is recognized. It is a mechanism to serve as a role model for others-regardless of gender, race, sexual orientation, religion, socio-economic status, level of education, etc. And, I get to do this in the same manner that it was bestowed upon me: through compassion. It means that as a Hispanic mathematics educator, I am valued.

-Hortensia Soto

\section{Biography}

Dr. Hortensia Soto was born in Jalisco, Mexico. When she was one, she and her older sister and parents immigrated to rural western Nebraska, where she was raised on a farm. This is where she learned the value of a strong work ethic; it is also where she learned that she wanted an education. Her parents, who both have a third-grade education, taught her and modeled that through hard work, anything was possible. Dr. Soto is extremely grateful to her teachers who were patient with her, especially when she was first learning English.

Dr. Soto earned her degrees from Chadron State College, University of Arizona, and University of Northern Colorado. She is currently a professor in the School of Mathematical Sciences at the University of Northern Colorado, where she works with prospective and in-service K-16 mathematics teachers. Through her teaching, 
outreach efforts, and professional development, she always strives to "pay it forward" by opening doors for others as her teachers did for her.

As a mathematics educator, Dr. Soto publishes in various areas of mathematics education, including assessment, mathematical preparation of elementary teachers, outreach programs for high school girls, and especially in the area of teaching and learning of undergraduate mathematics. Her current research efforts related to the teaching and learning of complex analysis inform how to teach the course by blending geometric and algebraic reasoning. In her research and teaching, Dr. Soto adopts an embodied cognition perspective, which is a philosophy asserting that learning is body-based. As such, she creates embodied activities designed to invoke mathematical reasoning through physical or virtual human body experiences.

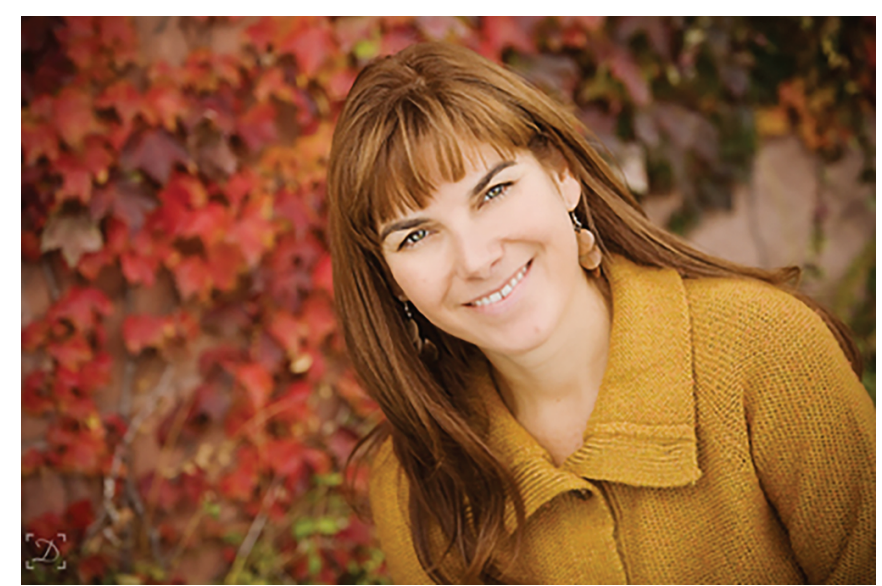

Hortensia Soto, Professor of Mathematics and Graduate Recruitment Coordinator, University of Northern Colorado.

Dr. Soto has facilitated professional development for K-16 teachers in Nebraska, Colorado, and California. In addition, she has taught teachers from rural Nebraska as part of the University of Nebraska-Lincoln NSF-funded project, Math in the Middle. As part of Project PROMESAS SSC (Pathways with Regional Outreach and Mathematics Excellence for Student Achievement in STEM), she provides professional development to collegiate teachers. This has been an opportunity for her to teach seasoned and novice teachers about rich mathematical tasks, student-centered learning, and sense of community-all with an eye towards equity in the mathematics classroom.

She is a long-time working member of the Mathematical Association of America and currently serves as the associate secretary. She is an editor of the MAA Instructional Practices Guide and the coordinator for SIGMAA RUME. She has served on the editorial board of Mathematics Teacher, published by the National Council of Teachers of Mathematics, and currently serves on the editorial board for the International Journal of Research in Undergraduate Mathematics. For twenty years, she has consulted for ACT, where she helps make decisions about mathematics problems and about policy. Most recently, Dr. Soto received the MAA Deborah and Franklin Tepper Haimo Award for Distinguished College or University Teaching of Mathematics.

\section{EnriqueTreviño}

I greatly enjoy reading about the achievements from other Hispanic mathematicians. My favorite part of Lathisms has been the podcast. It is great to hear about the life of other mathematicians. To listen to the struggles on their path and their resilience. Also to hear the joy mathematics brings to them.

-Enrique Treviño

\section{Biography}

Dr. Enrique Treviño grew up on the Ciudad Juarez-El Paso border. Commuting between Mexico and the US daily, he completed his undergraduate studies earning a baccalaureate degree in mathematics at the University of Texas at El Paso in 2006. He earned his PhD in mathematics, with an emphasis in number theory, from Dartmouth College under the guidance of Carl Pomerance. His first academic position was as a visiting assistant professor at Swarthmore College; he has been a faculty member at Lake Forest College since 2013, where he is now an associate professor.

Dr. Treviño became interested in mathematics as a career thanks to the Mexican Mathematical Olympiad, in which he participated as a student in 2000 and 2001. Since then he has worked to prepare gifted mathematics students from the state of Chihuahua for the Mexican Mathematical Olympiad and is one of the trainers for the Mexican teams that compete at the different international competitions. In this capacity, he has created problems for the Chihuahua Mathematical Olympiad exams from 2002 to 2010 (except for 2004), graded the exams, and selected the team to represent the state. Alongside David Cossio, he has led problem-solving strategies workshops for high school teachers in Ciudad Juárez and Chihuahua, and he participated as

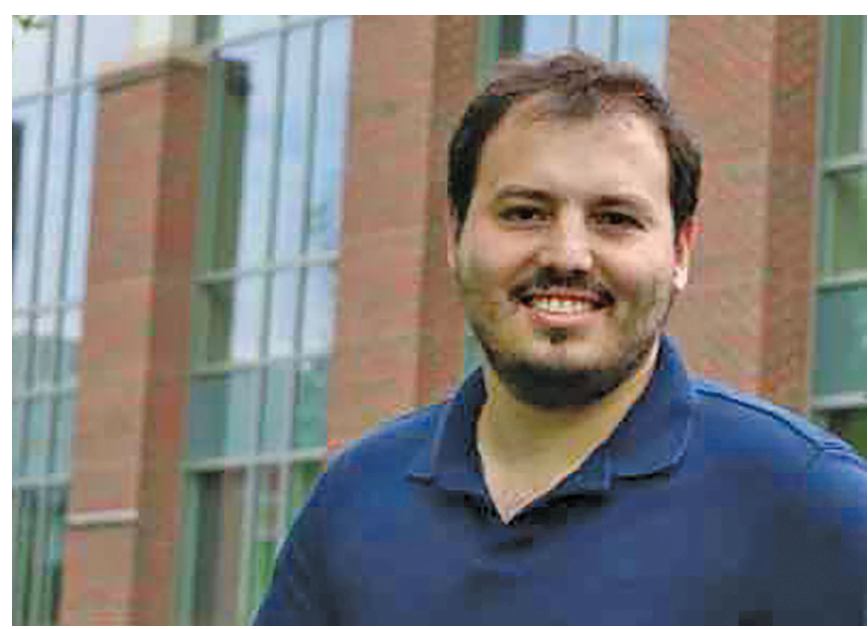

EnriqueTreviño, Associate Professor of Mathematics, Lake Forest College. 
a problem coordinator in the International Mathematical Olympiad in 2005, the Ibero-American Mathematical Olympiad in 2009, and the Mexican Mathematical Olympiad from 2015 to 2018. Starting in September 2019, he will lead the Mexican team at the Olimpiada Iberoamericana de Matemáticas. Dr. Treviño has also attended the last three European Girls Mathematical Olympiads as either a Leader (2018) or Deputy Leader $(2017,2019)$ of the Mexican teams and has been in charge of selecting the problems for the Asian Pacific Math Olympiad for the last two years. It is worth noting that the majority of competitions and training in Mexican states happen without financial support and are only possible thanks to volunteers like Dr. Treviño.

Dr. Treviño's main research interest is number theory. His PhD dissertation, titled "Numerically Explicit Estimates for Character Sums," involves a blend of analytic number theory and some serious computing. He has worked on problems such as estimating the least quadratic nonresidue modulo a prime, the least inert prime in a real quadratic field, and other concrete inequalities. Besides number theory, he writes recreational mathematics papers, cares deeply about undergraduate research, and works every summer on research projects with undergraduates. His work has resulted in five coauthored papers with undergraduates.

With respect to teaching, Dr. Treviño has taught nearly two dozen distinct courses as a college professor, including courses such as Programming, Calculus, Abstract Algebra, Combinatorics, Number Theory, and Recreational Mathematics. He likes to incorporate ideas from recreational mathematics in all classes he teaches, with the aim of getting students to see the fun side of mathematics. He has also taught at the Ross Program Asia, a program aimed at high school students interested in advanced mathematics, and at Awesome Summer Camp, a summer math camp for mathematically strong middle school and high school students who want to learn mathematics through problem solving.

\section{Vilma Mesa}

To me, Hispanic Heritage Month is an opportunity for all US residents to learn about the role that colonialism has played in the oppression of Latin America. I cherish our language, music, food, literature, festivals, dances, stories, sayings, and fiestas, and take any opportunity to share them. I dream of a day in which we reestablish our deep connections to our Native American ancestors and rescue their wisdom to guide our future.

- Vilma Mesa

\section{Biography}

Dr. Vilma Mesa earned a BS in computer sciences and a BS in mathematics from the University of Los Andes in Bogotá, Colombia, and prior to her career in education, Dr. Mesa was a systems programmer for the ministry of finances in Colombia and for the District of Bogotá and systems advisor for a large firm in Colombia. She earned

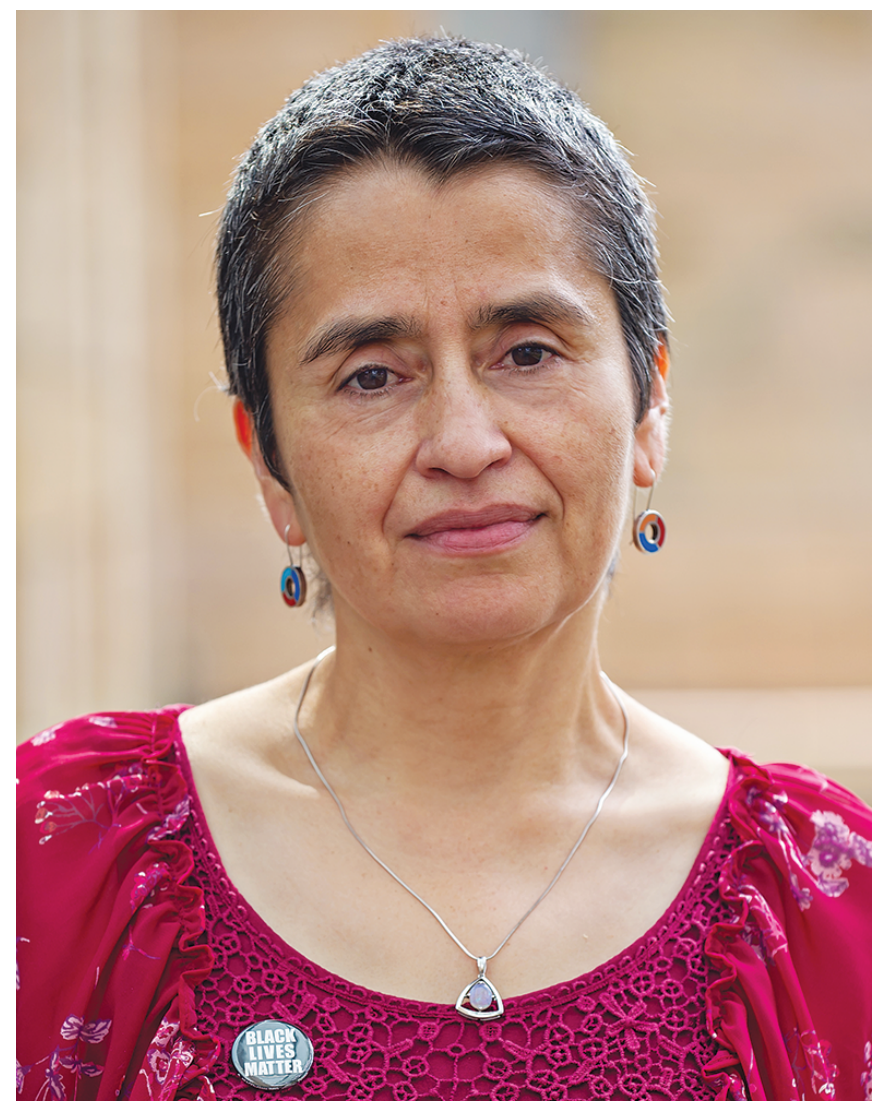

Vilma Mesa, Professor of Education and of Mathematics, University of Michigan.

a master's and a PhD in mathematics education from the University of Georgia; and Dr. Mesa is now professor of education and mathematics at the University of Michigan and faculty associate at the Center for the Study of Higher and Post-Secondary Education at the University of Michigan.

Dr. Mesa's research investigates the role that resources play in developing teaching expertise in undergraduate mathematics, specifically at community colleges and in inquiry-based learning classrooms. Her overarching research goal is to understand how textbooks, instructors, and students interact in order to create opportunities for students to learn mathematics in postsecondary education. With that goal in mind, her work is located at the intersection of three fields of scholarly inquiry: undergraduate mathematics education, mathematics education writ large, and higher education. Through her research she seeks to contribute theoretically grounded, empirically based observations that provide the foundation for knowledge claims and insights that can guide reform of mathematics instruction in postsecondary institutions, with particular emphasis on the important and understudied area of community college mathematics education.

Dr. Mesa has collaborated in evaluation projects on the impact of innovative mathematics teaching practices for students in STEM fields. As part of the National Study 
of Calculus, in collaboration with the Mathematical Association of America and funded by the National Science Foundation, she was in charge of the two-year college case studies. Dr. Mesa collaborates with various practitioners and researchers in several federally funded grants investigating the quality of mathematics instruction at community colleges, the uses of open-source textbooks in university settings, and the transparency of programs supporting students in transitioning to Calculus 2 at minority-serving community colleges. Dr. Mesa's work in mathematics education has produced more than forty published research articles.

Dr. Mesa has served as associate editor for the Journal for Research in Mathematics Education from 2000 to 2004 and is currently serving as associate editor for Educational Studies in Mathematics. She serves on the Curriculum Renewal Across the First Two Years MAA committee, on the board of the Mathematics Learning by Inquiry initiative, and as treasurer for the MAA special interest group in Research in Undergraduate Mathematics Education. She is an editorial board member for the International Journal for Research in Undergraduate Mathematics Education, Revista Pensamiento Numérico Avanzado, and Revista Educación Matemática.

\section{James Álvarez}

Hispanic Heritage Month highlights the important, complex history and contributions of Hispanics in our country. In my own ancestry, I have Tejanos in which the border crossed them in 1830s, Mexicans who crossed the border in the 1850s and 1890s, and my father who left Spain in 1963. My parents always emphasized the power of knowledge and facts in combating racism. Thus, I always viewed knowing our history as an integral part of helping others understand the rich contributions Hispanics have made to this country from cowboy traditions in the southwest to a current day Supreme Court justice.

—James Álvarez

\section{Biography}

Dr. James A. Mendoza Álvarez grew up on his family's farm near Saspamco, Texas, south of San Antonio. The story of his great grandparents' walk across the border from Mexico in 1890 and their tenacity in saving for ten years to purchase a "rancho" on wages of 25 cents per day in a nearby brick factory grounded his upbringing in the values of perseverance and hard work. Both his father, who emigrated from Spain in 1963, and his mother were school teachers who prioritized the pursuit of higher education. His mother's passion for teaching highly influenced his own desire to be an educator.

Dr. Álvarez earned his BS degree in mathematics and physics from Texas A\&M University-Commerce and completed his PhD at The University of Texas. His passion for issues related to equity and access in mathematics fueled his move to research in mathematics education. Thus, immediately after completing his PhD, Dr. Álvarez took a postdoctoral position in mathematics education at the Charles A. Dana Center at The University of Texas at Austin. Dr. Álvarez is currently a professor of mathematics and Distinguished Teaching Professor at The University of Texas at Arlington and graduate director of the MA in Mathematics Program for secondary mathematics teachers. He is happily married to Dr. Minerva Cordero (also a mathematician), and they have two grown sons, Alex and Nicholas.

Dr. Álvarez's research and professional interests are in mathematics education with a focus on mathematical problem solving, mathematics-specific technology, increasing access to mathematics through improved preparation of mathematics teachers, program development, and curriculum development. In the K-12 setting, he has been an essential contributor to the development and enhancement of mathematics standards and assessments for students and teachers.

Dr. Álvarez is an advocate for increasing access to STEM by improving teacher preparation, facilitating professional development opportunities for teachers, and promoting programs that enhance mathematical experiences at the K-12 and college level. Throughout his career, Dr. Álvarez has worked on several initiatives aimed at increasing the participation of historically underserved populations in

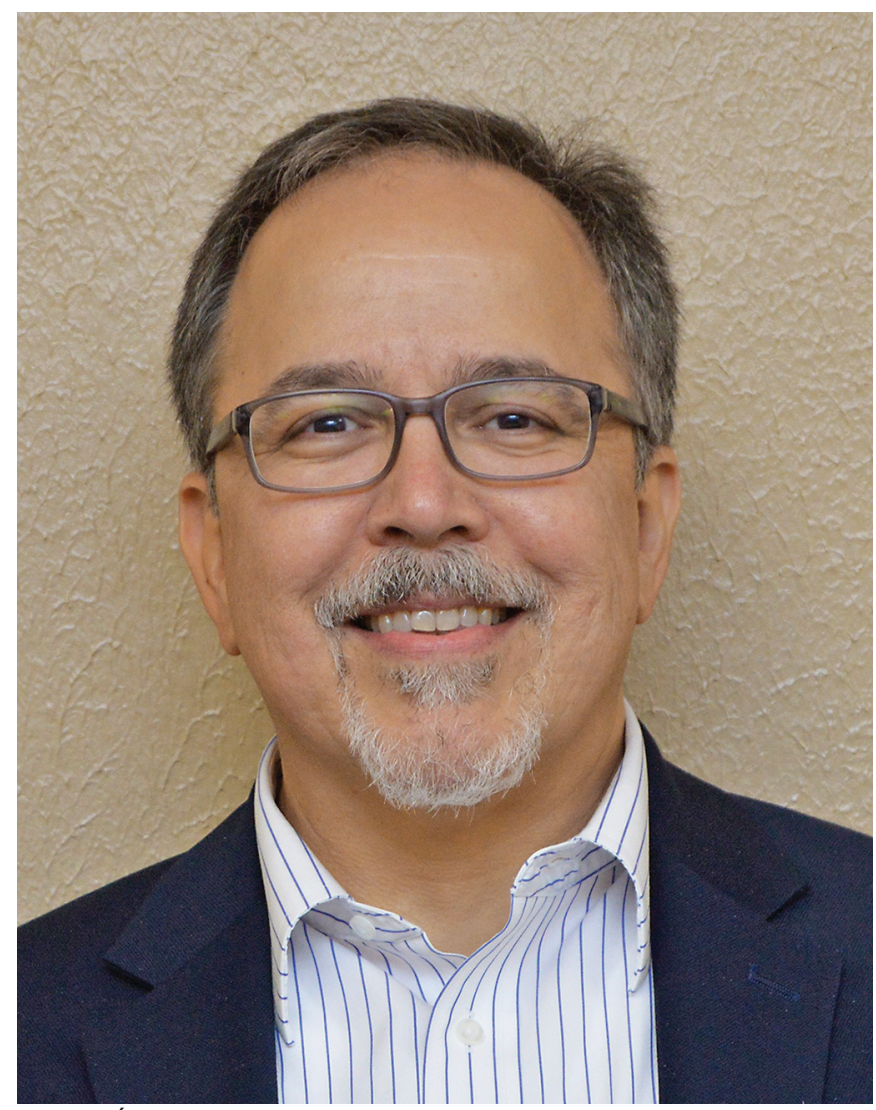

James Álvarez, Professor of Mathematics and Distinguished Teaching Professor, University of Texas at Arlington. 


\section{COMMUNICATION}

the mathematical sciences, including working extensively with the Emerging Scholars Program (ESP), which focuses on increasing success rates in calculus, especially for Latinx and African American students. Dr. Álvarez has instructed hundreds of faculty and graduate students nationwide on task development, problem solving, and instructional practices essential for successful ESP programs.

Dr. Álvarez's accomplishments have been recognized at several levels. Most recently he was awarded the 2016 UT Arlington Outstanding Honors College Faculty Award, the 2017 Texas Section of the MAA Distinguished Service award, an MAA Certificate of Meritorious Service, and the 2017 E. Glenadine Gibb Achievement Award of the Texas Council of Teachers of Mathematics. Moreover, he is a six-time recipient of a UT Arlington Provost's Research Excellence Award in the College of Science.

ACKNOWLEDGMENTS. We would like to thank Dr. Guadalupe Lozano, who was instrumental in the development of the 2019 Lathisms theme of mathematical education. We also thank the AMS and MAA for their continued support.

\section{Credits}

Photo of Hortensia Soto is courtesy of Photography by Desiree.

Photo of Enrique Treviño is courtesy of Lake Forest College. Photo of Vilma Mesa is courtesy of Leisa Thompson.

Photo of James Álvarez is courtesy of Greg Pederson. 